\title{
Selective Disruption of Inhibitory Synapses Leading to Neuronal Hyperexcitability at an Early Stage of Tau Pathogenesis in a Mouse Model
}

\author{
Masafumi Shimojo, ${ }^{1}$ Hiroyuki Takuwa, ${ }^{1}$ Yuhei Takado, ${ }^{1}$ Masaki Tokunaga, ${ }^{1}$ Satoshi Tsukamoto, ${ }^{2}$ \\ Keiichiro Minatohara, ${ }^{1}$ Maiko Ono, ${ }^{1}$ Chie Seki, ${ }^{1}$ Jun Maeda, ${ }^{1}$ Takuya Urushihata, ${ }^{1}$ Takeharu Minamihisamatsu, ${ }^{1}$ \\ ${ }^{1}$ Ichio Aoki, ${ }^{3}$ Kazunori Kawamura, ${ }^{4}$ Ming-Rong Zhang, ${ }^{4}$ Tetsuya Suhara, ${ }^{1}$ Naruhiko Sahara, ${ }^{1}$ and \\ Makoto Higuchi ${ }^{1}$ \\ ${ }^{1}$ Department of Functional Brain Imaging, ${ }^{2}$ Laboratory Animal and Genome Sciences Section, ${ }^{3}$ Department of Molecular Imaging and Theranostics, \\ and ${ }^{4}$ Department of Radiopharmaceuticals Development, National Institutes for Quantum and Radiological Science and Technology, Chiba, \\ 263-8555, Japan
}

Synaptic dysfunction provoking dysregulated cortical neural circuits is currently hypothesized as a key pathophysiological process underlying clinical manifestations in Alzheimer's disease and related neurodegenerative tauopathies. Here, we conducted PET along with postmortem assays to investigate time course changes of excitatory and inhibitory synaptic constituents in an rTg4510 mouse model of tauopathy, which develops tau pathologies leading to noticeable brain atrophy at 5-6 months of age. Both male and female mice were analyzed in this study. We observed that radiosignals derived from [ $\left.{ }^{11} \mathrm{C}\right]$ flumazenil, a tracer for benzodiazepine receptor, in rTg4510 mice were significantly lower than the levels in nontransgenic littermates at 23 months of age. In contrast, retentions of $(\mathrm{E})-\left[{ }^{11} \mathrm{C}\right] \mathrm{ABP} 688$, a tracer for mGluR5, were unaltered relative to controls at 2 months of age but then gradually declined with aging in parallel with progressive brain atrophy. Biochemical and immunohistochemical assessment of postmortem brain tissues demonstrated that inhibitory, but not excitatory, synaptic constituents selectively diminished without overt loss of somas of GABAergic interneurons in the neocortex and hippocampus of rTg4510 mice at 2 months of age, which was concurrent with enhanced immunoreactivity of cFos, a well-characterized immediate early gene, suggesting that impaired inhibitory neurotransmission may cause hyperexcitability of cortical circuits. Our findings indicate that tau-induced disruption of the inhibitory synapse may be a critical trigger of progressive neurodegeneration, resulting in massive neuronal loss, and PET assessments of inhibitory versus excitatory synapses potentially offer in vivo indices for hyperexcitability and excitotoxicity early in the etiologic pathway of neurodegenerative tauopathies.

Key words: Alzheimer's disease; E/I balance; PET; synapse; tau

\section{Significance Statement}

In this study, we examined the in vivo status of excitatory and inhibitory synapses in the brain of the rTg4510 tauopathy mouse model by PET imaging with (E)-[ $\left.{ }^{11} \mathrm{C}\right] \mathrm{ABP} 688$ and $\left[{ }^{11} \mathrm{C}\right]$ flumazenil, respectively. We identified inhibitory synapse as being significantly dysregulated before brain atrophy at 2 months of age, while excitatory synapse stayed relatively intact at this stage. In line with this observation, postmortem assessment of brain tissues demonstrated selective attenuation of inhibitory synaptic constituents accompanied by the upregulation of cFos before the formation of tau pathology in the forebrain at young ages. Our findings indicate that selective degeneration of inhibitory synapse with hyperexcitability in the cortical circuit constitutes the critical early pathophysiology of tauopathy.

Received Dec. 3, 2019; revised Mar. 12, 2020; accepted Mar. 13, 2020.

Author contributions: M.S., H.T., Y.T., and M.H. designed research; M.S., H.T., Y.T., M.T., S.T., T.M., I.A., K.K., and M.-R.Z. performed research; M.S., K.M., M.O., C.S., J.M., and T.U. analyzed data; M.S., T.S., N.S., and M.H. wrote the paper.

This work was supported in part by AMED Grants JP19dm0207072 to M.H., JP19dk0207049 to M.H., JP18dm0107062 to N.S., and 17dm0107066h to I.A.; JST CREST Grant JPMJCR1652 to M.H.; Center of Innovation Program JPMJCE1305 to I.A.; and JSPS KAKENHI Grants 6K21636, 18H04752, and 18K07777 to M.S. We thank Shoko Uchida and Kaori Yuki for technical assistance; and all laboratory members for discussions and encouragement.

The authors declare no competing financial interests.

Correspondence should be addressed to Makoto Higuchi at higuchi.makoto@gst.go.jp.

https://doi.org/10.1523/JNEUROSCI.2880-19.2020

Copyright $\odot 2020$ the authors

\section{Introduction}

Progressive neurodegeneration with deposition of intracellular inclusions represented as neurofibrillary tangles (NFTs), composed of hyperphosphorylated microtubule-associated protein tau, is a common pathological hallmark of tauopathy spectrum disorders, including Alzheimer's disease (AD) and frontotemporal lobar degeneration (Morris et al., 2011; Iqbal et al., 2016). Deposition of NFT is initiated in the entorhinal cortex and spread through limbic and neocortical areas during the course of AD progress (Braak and Braak, 1991), and the distribution of 
NFTs is well correlated with the severity of brain atrophy and cognitive decline (Arriagada et al., 1992; Giannakopoulos et al., 2003). In the last two decades, several genetically engineered mouse models were developed that could reproduce NFT-like deposition accompanied by progressive neuronal loss with impairment of cognitive and memory behaviors (Jankowsky and Zheng, 2017). More recently, PET imaging with tau-specific radioactive tracers enabled noninvasive visualization of the tau pathology in living subjects (Maruyama et al., 2013). Therefore, translational approaches to exploring the molecular basis of the tau-associated pathophysiology in these animal models are providing crucial information for accomplishing future clinical diagnoses and pharmacological therapy in humans.

Cumulative evidence has indicated that synaptic dysfunction accompanied by aberrant activity in the neocortical neuronal circuit is a critical feature in a preclinical stage of $\mathrm{AD}$ (Palop and Mucke, 2016). Synaptic degeneration precedes neuronal loss and best correlates with tau pathology and cognitive performance in dementing illnesses (SpiresJones and Hyman, 2014). In mice, several independent lines of tauopathy models have demonstrated increased vulnerability for epileptogenesis before abundant tau depositions and neuronal loss (GarcíaCabrero et al., 2013; Maeda et al., 2016; Liu et al., 2017). In contrast, genetic deletion of endogenous tau significantly attenuates seizure susceptibility in mouse models of AD and drug-induced epilepsy (Palop et al., 2007; Roberson et al., 2007). Although tau is mainly distributed in axons for the maintenance of microtubule dynamics, several studies have also indicated that tau localizes into presynapses and postsynapses and regulates synaptic function (Ittner et al., 2010; Kimura et al., 2014). Abnormal alteration of spine density and turnover associated with tau accumulation in cortical and hippocampal pyramidal neurons has been observed (Rocher et al., 2010; Kopeikina et al., 2013; Jackson et al., 2017), which may also cause synaptic impairment by affecting the intracellular calcium homeostasis and the recycling of glutamate receptors (Hoover et al., 2010; Zhao et al., 2016; Busche et al., 2019). These findings indicate that tau pathogenesis is tightly linked to synaptic dysfunction with the hyperexcitability of the neuronal circuit. Nevertheless, it is still uncertain whether tau toxicity predominantly impacts excitatory or inhibitory synapses, causing abnormal network activity of the cortical circuit, particularly in the early stage of the pathological cascade.

To address this crucial issue, we sought to investigate the agedependent alteration of excitatory and inhibitory synapses in the brains of the rTg4510 tauopathy mouse model by PET imaging. This transgenic mouse strain overexpresses frontotemporal
B

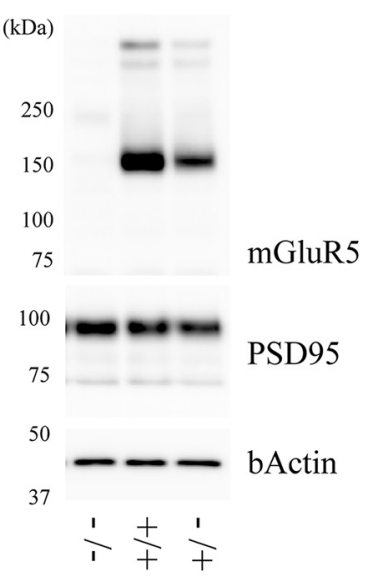

D
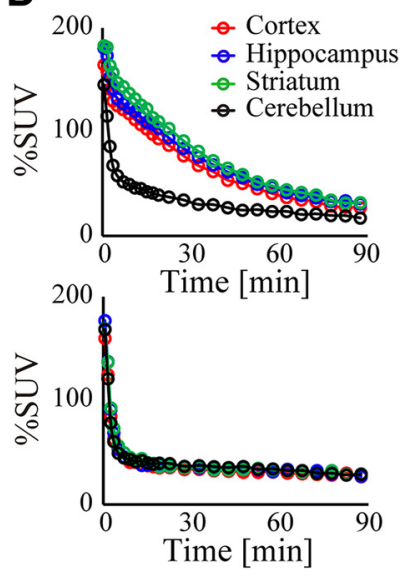

$\left.\begin{array}{cc}30 & 60 \\ \text { Time } & {[\mathrm{min}}\end{array}\right]$ 90
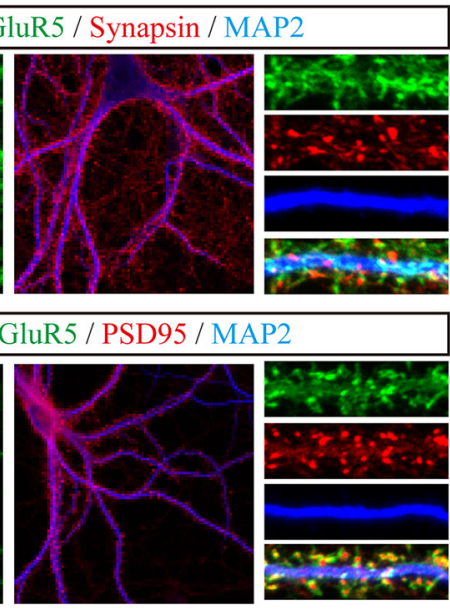

(E)-[ $\left.{ }^{11} \mathrm{C}\right] \mathrm{ABP} 688$ PET

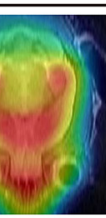

$\%$ SUV

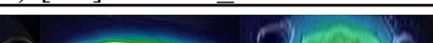

Figure 1. Validation of $(E)-\left[{ }^{11} C\right] A B P 688$ PET tracer in the mGluR5-deficient mouse. $A$, Subcellular distribution of HA-tagged mGluR5 in DIV20 cortical neurons was analyzed by confocal microscopy. Neurons were immunostained with antibodies demonstrated. B, Brain homogenates from 6-month-old WT $(+/+)$, heterozygous $(+/-)$, and homozygous $(-/-)$ GluR5 $\mathrm{KO}$ mice were analyzed by immunoblotting with indicated antibodies. The protein levels of mGluR5 are reduced in a

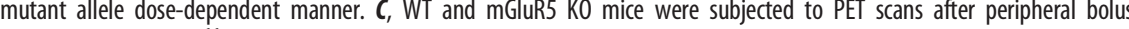
政 mice (bottom). Volumes of interest were manually placed on the neocortex, hippocampus, striatum, and cerebellum. The retention of radioactivity observed in WT forebrain was almost completely suppressed in mGluR5 KO forebrain.

dementia with Parkinsonism-linked chromosome-17 (FTDP-17) associated P301L mutant form of human tau in excitatory neurons of forebrains, and typically develops NFT-like depositions by 4-5 months of age followed by progressive neuronal loss and atrophy in the neocortex and hippocampus by 6 months of age (Ramsden et al., 2005; Santacruz et al., 2005; Ishikawa et al., 2018). We recently developed (E)- $\left[{ }^{11} \mathrm{C}\right] \mathrm{ABP} 688$, a highly selective radioactive tracer binding to the allosteric site of metabotropic glutamate receptor subtype 5 (mGluR5) in the excitatory synapse, and accomplished longitudinal visualization of mGluR5 protein in animal brains (Kawamura et al., 2014; Yamasaki et al., 2016). Using (E)- $\left[{ }^{11} \mathrm{C}\right] \mathrm{ABP} 688$ and $\left[{ }^{11} \mathrm{C}\right]$ flumazenil, a well-characterized radioactive $\mathrm{PET}$ tracer for benzodiazepine receptor corresponding to subunits $\alpha$ and $\gamma$ of $\mathrm{GABA}_{\mathrm{A}}$ receptor, we can demonstrate the dynamic alteration of excitatory and inhibitory synaptic status associated with neuronal activity during the tauinduced pathological cascade. 
A

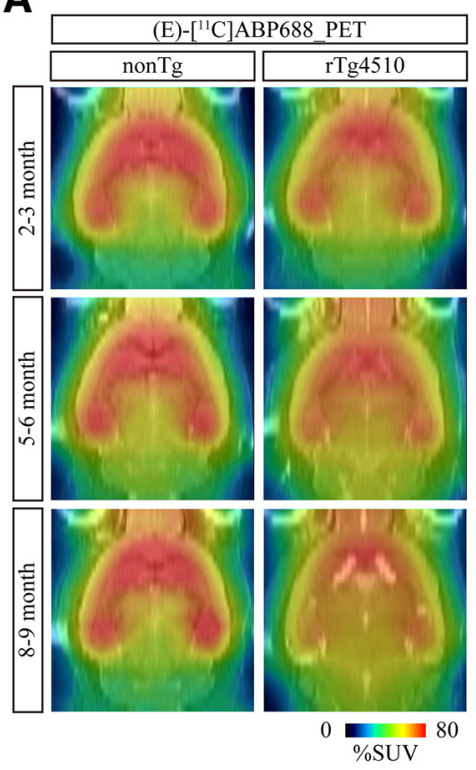

B $\square \operatorname{nonTg} \square \operatorname{rTg} 4510$
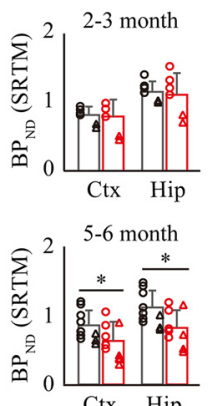

Ctx Hip

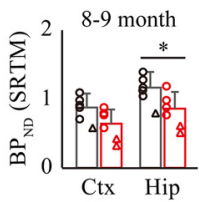

Ctx Hip
C

nonTg $\square \mathrm{rTg} 4510$
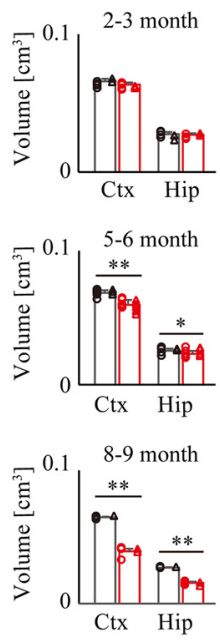

Figure 2. PET assessment of excitatory synapse with (E) $\left[{ }^{11} C\right] A B P 688$ in $\mathrm{rTg} 4510$ brain. $\boldsymbol{A}$, NonTg and $\mathrm{rTg} 4510$ mice were subjected to PET scans at age 2-3 months (top panels), 5-6 months (middle panels), and 8-9 months (bottom panels) after peripheral bolus administration of (E) $-\left[{ }^{11} \mathrm{C}\right] \mathrm{ABP} 688$. Representative PET images generated by averaging dynamic scan data at 0-90 min are shown. MR images of individual animals were captured and overlaid for spatial alignment and volumetric assessment. $\boldsymbol{B}$, Age-dependent alteration of $\mathrm{BP}_{\mathrm{ND}}$ with (E)- $\left.{ }^{11} \mathrm{C}\right] \mathrm{ABP} 688$ PET was analyzed in cortex (Ctx) and hippocampus (Hip) by Simple Reference Tissue Model with cerebellum as reference region. Data from 5-10 mice/genotype at 23 months (top graphs), 5-6 months (middle graphs), and 8-9 months (bottom graphs) of age are plotted as mean \pm SD. Each circle represents an individual male mouse. Each triangle represents an individual female mouse. ${ }^{*} p<0.05$ (MannWhitney test). C, MRI volumetric analysis of neocortex (Ctx) and hippocampus (Hip) from nonTg and rTg4510 mice. Data from 5-10 mice/genotype at age 2-3 months (top graphs), 5-6 months (middle graphs), and 8-9 months (bottom graphs) are plotted as mean $\pm S D$. Each circle represents an individual male mouse. Each triangle represents an individual female mouse. ${ }^{*} p<0.05$; ${ }^{* *} p<0.01$; Student's $t$ test.

\section{Materials and Methods}

\section{Animals}

All mice used in this study were kept in a $12 \mathrm{~h}$ light/dark cycle with ad libitum access to standard diet and water. NonTg, CaMKII-tTA, TauResponder, and $\mathrm{rTg} 4510$ mice (male 75, female 26, age range 210 months) were generated by cross-breeding of tau responder transgenic line (tetO-MAPT ${ }^{*} \mathrm{P} 301 \mathrm{~L}, \mathrm{FVB} / \mathrm{N}$ background) and tTA activator transgenic line (Camk2a-tTA, 129/SV background) as described previously (Ishikawa et al., 2018). mGluR5 KO mice were generated by the deletion of a large fragment of exon 3 (containing ATG translation initiation codon) by CRISPR-CAS9 system. Two guide RNAs (gRNAs) were designed to delete exon three of Grm5, and synthesized from $130 \mathrm{bp}$ of chemically synthesized double-stranded DNA (Integrated DNA Technologies), including T7 promoter, gRNA target sequences (GA?A3B2AGTGCACAGTCCAGTGAG and GTCTCAGCTGTGCA CACAGA) and gRNA-scaffold sequence as a template using the MEGA short script T7 Transcription Kit (Invitrogen) followed by the MEGA clear kit for RNA purification (Invitrogen). Embryo manipulation and microinjection were performed as previously described (Tatsumi et al., 2018). Briefly, MII oocytes were collected from superovulated C57BL/6J females (8-12 weeks old, Japan SLC) and fertilized in vitro, and cultured in KSOM medium until use. Fertilized 1-cell embryos were microinjected with a mixture of recombinant Cas 9 protein $(50 \mathrm{ng} / \mu \mathrm{l}$, Nippon Gene) and 2 gRNAs $(25 \mathrm{ng} / \mu \mathrm{l})$ into the cytoplasm. After the microinjection, the embryos were cultured in KSOM medium until the 2-cell stage and transferred to the oviduct of pseudopregnant ICR females (CLEA Japan) on the day of the vaginal plug (day 0.5). Genomic tail DNAs of these F0 founders were extracted and used for genotyping by PCR using the primers ATGCACCACTCAGCACAGAA and GCTGTTGTCAGC AGAATTTGAA. The PCR product of the WT allele is $976 \mathrm{bp}$, and the

mutant allele yields a $392 \mathrm{bp}$ product. F0 founders harboring deletion mutant were bred to WT C57BL/6J mice to generate heterozygously, and they were maintained on the genetic background of C57BL/6J for this study. All experimental procedures related to animals and their care were approved by the Animal Ethics Committee of the National Institutes for Quantum and radiologic Science and Technology.

\section{Animal PET/MRI}

Animal PET imaging was conducted using the microPET Focus 220 system (Siemens Medical Solutions) as previously described (Tokunaga et al., 2009). Age-matched nonTg and rTg4510 mice were anesthetized with $1.5 \%-2.0 \%$ isoflurane and had a $31 \mathrm{G}$ needle with polyethylene catheter inserted into the tail vein. (E) $-\left[{ }^{11} \mathrm{C}\right]$ $\mathrm{ABP} 688$ and $\left[{ }^{11} \mathrm{C}\right]$ flumazenil were radiosynthesized as described previously (Nishino et al., 2016; Yamasaki et al., 2016). A dynamic emission scan in 3D list mode was performed immediately after intravenous bolus injection of (E)- $\left[{ }^{11} \mathrm{C}\right] \mathrm{ABP} 688(35.1 \pm 4.3 \mathrm{MBq})$ or $\left[{ }^{11} \mathrm{C}\right] \mathrm{flu}-$ mazenil (30.5 $\pm 5.5 \mathrm{MBq})$. MRI analysis was conducted with a $7.0 \mathrm{~T}$ horizontal MRI scanner (Bruker Biospin) with a volume coil for transmission (Bruker Biospin) and a 2-ch phasedarray surface coil (Rapid Biomedical) as described previously (Ishikawa et al., 2018). Briefly, mice were anesthetized with 1.5\%-2.0\% isoflurane, and their rectal temperature was maintained at $36.5 \pm 0.5^{\circ} \mathrm{C}$ with a heating pad and warm air during the experiment. T2weighted MR images were obtained by rapid acquisition with relaxation enhancement sequence and the following parameters: repetition time $=$ $4200 \mathrm{~ms}$, effective echo time $=36 \mathrm{~ms}$, fat suppression $=$ on, number of average $=4$, rapid acquisition with relaxation enhancement factor $=8$, number of slices $=13$, and scan time $=6 \mathrm{~min} 43 \mathrm{~s}$. All acquired PET and MR images were coregistered and analyzed using PMOD software (PMOD Technologies). Volumes of interest were manually generated by anatomic alignment with the cortex, hippocampus, brainstem, and cerebellum of MR images. For quantification of regional radioactivities, dynamic images were reconstructed, and the averaged radioactive signal in each volume of interest was calculated as \% standardized uptake value (representing the $\%$ injected dose per $\mathrm{cm}^{3}$ volume compensated by body weight). For comparison of genotypes, binding potential $\left(\mathrm{BP}_{\mathrm{ND}}\right)$ was calculated for (E)- $\left[{ }^{11} \mathrm{C}\right] \mathrm{ABP} 688$ based on a simplified reference tissue model with cerebellum reference. For $\left[{ }^{11} \mathrm{C}\right]$ flumazenil, the $\%$ standardized uptake value ratio (SUVR) with brain stem reference was analyzed.

\section{Antibodies}

Mouse monoclonal Tau-5 and Tau-12 antibodies were a kind gift from Drs. Lester I. Binder and Nicholas M. Kanaan (Michigan State University). The following antibodies were purchased from commercial sources and used for immunoblotting and immunohistochemical analysis: mouse anti-human tau (HT7, MN1000) and mouse antiphosphorylated tau (AT-8, MN1020) from Thermo Fisher Scientific; mouse anti-NeuN (MAB377), mouse anti-GluN1 (MAB363), mouse anti-GAD65 (ABN101), mouse anti-GAD67 (MAB5406), mouse antiparvalbumin (PV) (MAB1572), mouse anti-CaMKII $\alpha$ (05-532), rabbit anti-mGluR5 (AB5675), rabbit anti-Synapsin I (AB1543P), and guinea pig anti-vGluT1 (AB5905) from Millipore; rabbit anti-NeuN (\#12943S) and rabbit anti-cFos (\#2250) from Cell Signaling Technology; mouse anti- $\beta$-actin (A1978) and rabbit anti-GABA (A2052) from Sigma Millipore; mouse anti-PSD95 (75-028) from NeuroMab; mouse antiSynapsin (106011), rabbit anti-Homer1 (160003), rabbit anti-VGAT 
(131013), and rabbit anti-GABA $A_{A}$ receptor subunit $\alpha 1$ (224203) from Synaptic Systems; rabbit anti-CDP/Cux1 (sc-13024) from Santa Cruz Biotechnology; chicken anti-MAP2 (AB5392) from Abcam; and mouse anti-HA (MMS-101R) from Covance.

\section{Biochemistry}

Preparation and analysis of brain lysate were performed as described previously with slight modification (Shimojo et al., 2019). Briefly, agematched nonTg and rTg4510 mice were housed in home cages until just before being killed by cervical dislocation at 2, 4, 6, 8, and 10 months of age. Forebrains were quickly dissected and kept frozen until before use. Brain tissues were homogenized in 20 mM HEPES-NaOH, pH 7.4, 150 mM NaCl, 2 mм EDTA supplemented with protease inhibitor cocktail (Roche Diagnostics) and phosphatase inhibitors (Sigma Millipore) by tissue grinder, and lysed by the addition of SDS-PAGE sample buffer with further resuspension using a $26 \mathrm{G}$ needle. Extracted proteins were separated by SDS-PAGE with precast Tris-glycine acrylamide gels (Nacalai), transferred to a nitrocellulose membrane, and analyzed by conventional immunoblot procedures. Chemiluminescent signal was elicited using ECL (Pierce) reagents and detected by 600 (GE Healthcare). For quantification of signal intensity in each protein band, the ROI was manually placed and analyzed by Image J software.

\section{Immunohistochemistry}

Age-matched nonTg and rTg4510 male mice were housed in home cages until just before being killed by cervical dislocation, and brain tissues were quickly removed and fixed in 4\% PFA in PBS for $4 \mathrm{~h}$; 70- $\mu$ m-thick coronal slices were prepared by VT1200S (Leica Microsystems), blocked, and immunostained with various primary antibodies, followed by probing with secondary antibodies conjugated to Alexa-488, -546 , or -633 (Invitrogen). Fluorescence images were captured by FV1000 laser scanning confocal microscopy (Olympus) with either $\times 10$ (UPlanSApo, NA 0.40 ) or $\times 20$ (UPlanSApo, NA 0.75), or LSM880 laser scanning confocal microscopy (Carl Zeiss) with either $\times 10$ (Plan-Apo, NA 0.45 ), $\times 20$ (Plan-Apo, NA 0.8), or $\times 63$ (Plan-Apo, NA 1.4) objectives. For quantifying the density of various markers (NeuN, GABA, PV, cFos, HT7, and AT8), $z$-stacked images (total $10 \mu \mathrm{m}$ thickness) were acquired in hippocampal CA1 and somatosensory cortex from each mouse brain and projected to a single-plane image. Image processing, including thresholding, was applied, and the number of cells in the determined area was manually counted with Cell Counter plugin of Image J/Fiji software. For voxel-based analysis of excitatory and inhibitory synaptic puncta, high magnification $z$-stacked optical slices (total $4 \mu \mathrm{m}$ thickness) were captured, and the number of synaptic puncta was analyzed in 3D stack volumes with blob finder function of Arivis Vision 4D software.

\section{Immunocytochemistry}

The dissociated cortical neurons from E18.5 mouse embryos were plated onto poly-D-lysine (Sigma Millipore)-coated $18 \mathrm{~mm}$ glass coverslips at a density of 200,000-250,000 cells $/ \mathrm{cm}^{2}$ and grown in Neurobasal medium (Thermo Fisher Scientific) supplemented with 2\% FBS (HyClone), Glutamax (Thermo Fisher Scientific), and B27 (Thermo Fisher Scientific). Neurons were infected with recombinant lentiviruses expressing HA-tagged mGluR5 at DIV4 and further maintained by replacing $50 \%$ of the medium with fresh serum-free medium every 3-4 d. At DIV 20, neurons were fixed, permeabilized, and blocked in a solution containing 4\% BSA (Sigma Millipore) and $4 \%$ horse serum followed by immunolabeling with primary and secondary antibodies. Fluorescence images were then acquired by FV1000 laser scanning confocal microscopy with $\times 60$ oil immersion objective (UPlanSApo, NA1.43).

\section{Experimental design and statistical analyses}

We preferred to use male mice as much as possible to minimize potential variability caused by sex difference, but we analyzed both genders in this
A

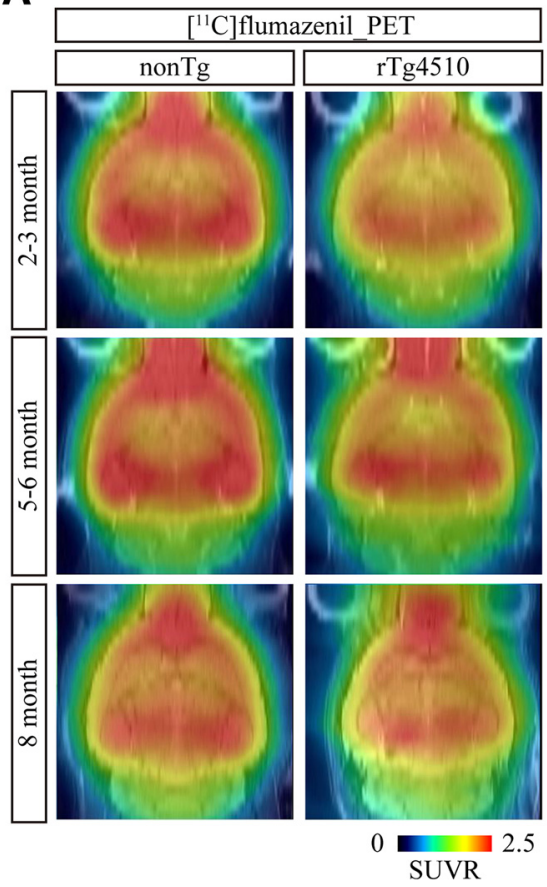

B

$\square \operatorname{nonTg} \quad$ rTg4510
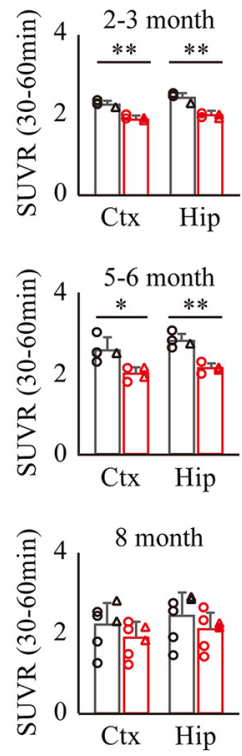

Figure 3. PET assessment of inhibitory synapse with $\left[{ }^{11} \mathrm{C}\right]$ flumazenil in $\mathrm{rTg} 4510$ brain. $\boldsymbol{A}$, NonTg and rTg4510 mice were subjected to PET scans at age 2-3 months (top panels), 56 months (middle panels), and 8 months (bottom panels) after peripheral bolus administration of $\left[{ }^{11} \mathrm{C}\right]$ flumazenil. Representative PET images generated by averaging dynamic scan data at 30-60 min are shown. MR images of individual animals were captured and overlaid for spatial alignment. $\boldsymbol{B}$, Age-dependent alteration of averaged SUVR with $\left[{ }^{11} \mathrm{C}\right.$ ]flumazenil PET was analyzed in cortex (Ctx) and hippocampus (Hip). Brainstem was set as reference region. Data from 4-6 mice/genotype at age 2 months (top graphs), 5 months (middle graphs), and 8 months (bottom graphs) are plotted as mean \pm SD. Each circle represents an individual male mouse. Each triangle represents an individual female mouse. ${ }^{*} p<0.05$; ${ }^{* *} p<0.01$; Student's $t$ test.

study because of limited availability of age-matched offspring in our bitransgenic mouse colony. For PET imaging with (E)-[ $\left[{ }^{11} \mathrm{C}\right] \mathrm{ABP} 688$, nonTg (2-3 months: male $=4$, female $=2$; 5-6 months: male $=7$, female $=3 ; 8-9$ months: male $=5$, female $=1)$ and $\mathrm{rTg} 4510(2-3$ months: male $=4$, female $=2 ; 5-6$ months: male $=5$, female $=5 ; 8-9$ months: male $=4$, female $=2$ ) mice were analyzed. For PET imaging with $\left[{ }^{11} \mathrm{C}\right]$ flumazenil, nonTg (2-3 months: male $=3$, female $=1 ; 5-6$ months: male $=3$, female $=1 ; 8$ months: male $=4$, female $=2)$ and $\mathrm{rTg} 4510(2-3$ months: male $=$ 2, female $=2 ; 5-6$ months: male $=2$, female $=2 ; 8$ months: male $=4$, female $=2$ ) mice were analyzed. All animals used for PET imaging subsequently underwent MR imaging for brain volume assessment and PET image alignment. For time course assessment of various synaptic markers, nonTg (2 months: male $=2$, female $=3 ; 4$ months: male $=3$, female $=2 ; 6$ months: male $=4$, female $=1 ;$ months: male $=2$, female $=$ 2; 10 months: male $=2$, female $=1$ ) and $\operatorname{rTg} 4510$ ( 2 months: male $=3$, female $=2 ; 4$ months: male $=4$, female $=1 ; 6$ months: male $=4$, female $=$ 1; 8 months: male $=2$, female $=2 ; 10$ months: male $=1$, female $=2$ ) were analyzed. For biochemical comparison of all genotypes, we analyzed 2-month-old male mice of nonTg $(n=4)$, CamK2a-tTA $(n=4)$, tetO$\mathrm{MAPT}^{*} \mathrm{P} 301 \mathrm{~L}(n=4)$, and $\mathrm{rTg} 4510(n=4)$. Immunohistochemical analysis was performed with nonTg $($ male $=14)$ and $\operatorname{rTg} 4510($ male $=14)$.

Statistics were analyzed with GraphPad Prism software (GraphPad). Student's $t$ test or Mann-Whitney test were used for comparison of two groups between age-matched nonTg and $\mathrm{rTg} 4510$. For multiple comparisons of all genotype groups generated by cross-breeding of TauResponder (tetO-MAPT`P301L) and CaMKII-tTA (Camk2a-tTA) lines, one-way ANOVA was used to determine differences between group means. If ANOVA was significant, differences between control group and other groups were analyzed by Dunnett post hoc test. 


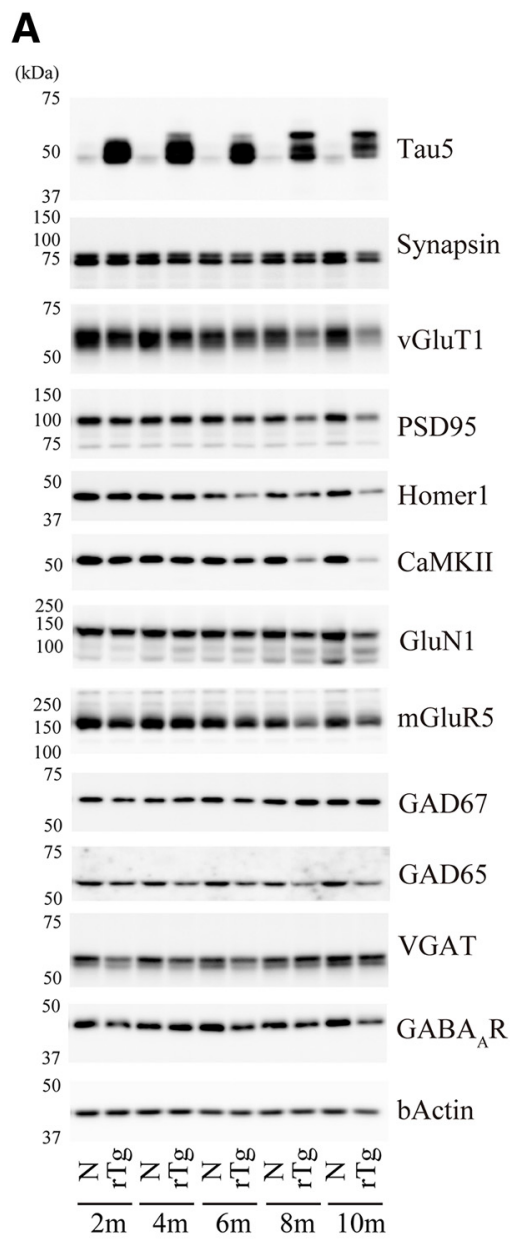

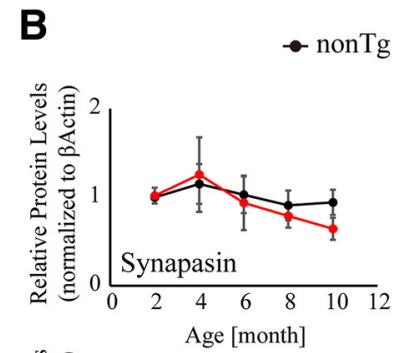
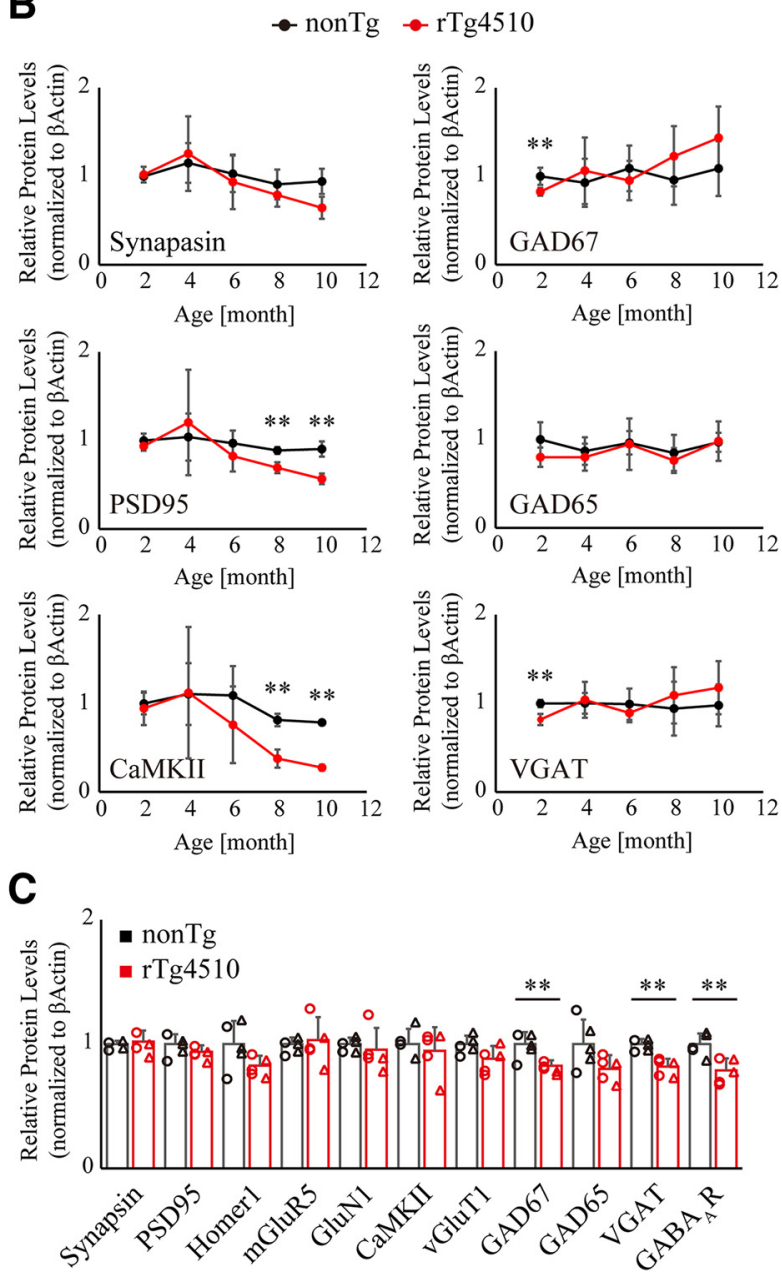

Figure 4. Biochemical profiling of synaptic markers in rTg4510 mouse forebrain homogenates. A, Forebrain homogenates from 2-, 4-, 6-, 8-, and 10-month-old nonTg and rTg4510 mice were systematically analyzed by immunoblotting with antibodies against excitatory and inhibitory synaptic proteins. Excitatory markers demonstrate progressive age-dependent decline, whereas inhibitory markers demonstrate significant attenuation in the early stage, which is followed by gradual restoration during the course of progressive tau pathology. $\boldsymbol{B}$, The age-dependent transition of protein levels in nonTg and rTg4510 forebrains. The protein level of each marker was normalized by the level of $\beta$-actin, and the mean value of nonTg at 2 months of age was set as 1. Data from 3-5 independent mouse brains are plotted as mean \pm SD. ${ }^{* *} p<0.01$ (Student's $t$ test). C, Selective decline of inhibitory markers in forebrain homogenate from 2month-old rTg4510. Mean value of nonTg mice was set as 1. Each circle represents an individual male mouse. Each triangle represents an individual female mouse. ${ }^{* *} p<0.01$ (Student's $t$ test).

\section{Results}

PET assessment of excitatory and inhibitory synapses in rTg4510 brain using (E)-[ $\left.{ }^{11} \mathrm{C}\right] \mathrm{ABP} 688$ and $\left[{ }^{11} \mathrm{C}\right]$ flumazenil To identify potential synaptic abnormalities associated with tau pathology, we first coordinated PET assessment of excitatory synapse in nonTg and $\mathrm{rTg} 4510$ brains with (E)-[ $\left.{ }^{11} \mathrm{C}\right] \mathrm{ABP} 688$, a selective PET tracer for metabotropic glutamate receptor subtype 5 (mGluR5). Recombinant mGluR5 was typically clustered in excitatory postsynaptic compartments in cultured neurons (Fig. 1A). Dynamic PET scan after bolus intravenous administration of $(\mathrm{E})-\left[{ }^{11} \mathrm{C}\right] \mathrm{ABP} 688$ demonstrated specific accumulation of radioactive signals in the forebrain, which was clearly diminished in mGluR5-deficient mice (Fig. $1 B-D$ ), supporting the sensitivity and specificity of this PET tracer. We observed that $\mathrm{BP}_{\mathrm{ND}}$ of $(\mathrm{E})$ $\left[{ }^{11} \mathrm{C}\right] \mathrm{ABP} 688$ in the neocortex and hippocampus of nonTg mice did not change during aging. In contrast, $\mathrm{BP}_{\mathrm{ND}}$ of $(\mathrm{E})-\left[{ }^{11} \mathrm{C}\right]$ ABP688 in the neocortex and hippocampus of rTg4510 mice was comparable with the levels of nonTg at 2-3 months of age but declined from 5-6 months of age, although no further decline was seen at $8-9$ months of age (Fig. $2 A, B$; nonTg vs rTg4510, cortex at $5-6$ months of age, $p=0.0431$; nonTg vs rTg4510, hippocampus at 5-6 months of age, $p=0.0232$; nonTg vs rTg4510, hippocampus at 8-9 months of age, $p=0.0478$, MannWhitney test). Although there was a trend of female mice to show lower $\mathrm{BP}_{\mathrm{ND}}$ of $(\mathrm{E})-\left[{ }^{11} \mathrm{C}\right] \mathrm{ABP} 688$ in both nonTg and rTg4510 groups, we could not detect any significant effect by gender difference in each condition, perhaps due to the limited female data. In good agreement with a previous study (Ishikawa et al., 2018), this time course was concurrent with the progressive atrophy of $\mathrm{rTg} 4510$ forebrain as determined by volumetric MRI (Fig. 2C; nonTg vs rTg4510, cortex at 5-6months of age, $t_{(18)}=6.785, p<0.0001$; nonTg vs rTg4510, hippocampus at 56 months of age, $t_{(18)}=2.475, p=0.0235$; nonTg vs rTg4510, cortex at $8-9$ months of age, $t_{(10)}=16.80, p<0.0001$; nonTg vs rTg4510, hippocampus at 8-9 months of age, $t_{(10)}=20.19$, $p<0.0001$, Student's $t$ test).

We next investigated the age-dependent alteration of inhibitory synapses in rTg4510 brains by PET imaging with $\left[{ }^{11} \mathrm{C}\right]$ flumazenil, a well-characterized radioactive PET tracer for benzodiazepine receptor corresponding to subunits $\alpha$ and $\gamma$ of $\mathrm{GABA}_{\mathrm{A}}$ receptor. Consistent with previous studies (Nishino et al., 2016; Müller Herde et al., 2017), intravenous injection 
of $\left[{ }^{11} \mathrm{C}\right]$ flumazenil followed by PET scan demonstrated that radioactive signal accumulated abundantly in the neocortex and hippocampus (Fig. 3A). Similar to the time course of $(\mathrm{E})-\left[{ }^{11} \mathrm{C}\right]$ ABP688 PET imaging, SUVR of $\left[{ }^{11} \mathrm{C}\right]$ flumazenil was fairly consistent in non $\mathrm{Tg}$ brains from 2 to 8 months of age (Fig. $3 A$, $B)$. Interestingly, we observed a significant reduction of SUVR in rTg4510 brains even at 2-3 months of age, and this suppressed level was maintained until 5-6 months of age (Fig. $3 A, B$; nonTg vs rTg4510, cortex at $2-3$ months of age, $t_{(6)}=7.988, p=0.0002 ;$ nonTg vs rTg4510, hippocampus at $2-3$ months of age, $t_{(6)}=7.002, p=0.0004 ;$ nonTg vs rTg4510, cortex at 5-6 months of age, $t_{(6)}=3.135, p=0.0202$; nonTg vs rTg4510, hippocampus at 5-6 months of age, $t_{(6)}=5.933, p=0.0010$, Student's $t$ test), suggesting that inhibitory synapse is disturbed at a relatively early stage of tau pathology in rTg4510 brains.

\section{Biochemical profiling of synaptic composition in rTg4510 mouse forebrain}

To obtain supportive evidence for our PET findings, we biochemically examined age-dependent alterations of excitatory and inhibitory synaptic proteins in postmortem forebrains of rTg4510 mice at ages ranging from 2 to 10 months.

Immunoblot assessment revealed that excitatory synaptic proteins, including PSD95, CaMKII, and mGluR5 in rTg4510 brains were within the range observed in age-matched nonTg brains until 6 months of age but then declined significantly at $\sim 8$ 10 months (Fig. $4 A, B$ nonTg vs rTg4510, PSD95 at 8 months of age, $t_{(6)}=5.324, p=0.0018 ;$ nonTg vs $\mathrm{rTg} 4510$, PSD95 at 10 months of age, $t_{(4)}=5.525, p=0.0052$; nonTg vs $\mathrm{rTg} 4510$, CaMKII at 8 months of age, $t_{(6)}=7.116, p=0.0004$; nonTg vs rTg4510, CaMKII at 10 months of age, $t_{(4)}=19.80, p<0.0001$, Student's $t$ test). In contrast, we observed that protein levels of GAD67, VGAT, and $\mathrm{GABA}_{\mathrm{A}} \mathrm{R}$ subunit $\alpha 1$ were significantly attenuated, by $20 \%, 18 \%$, and $22 \%$, respectively, at 2 months of age (Fig. $4 A-C$; nonTg vs rTg4510, GAD67, $t_{(8)}=3.666$, $p=0.0063$; nonTg vs rTg4510, VGAT, $t_{(8)}=5.392, p=0.0007$; nonTg vs rTg4510, GABA $\mathrm{R}, t_{(8)}=3.656, p=0.0064$, Student's $t$ test). However, we could not detect any difference in these protein levels between the two genotypes during age 4-10 months, presumably due to compensatory upregulation of inhibitory synaptic proteins or age-dependent loss of excitatory neurons and synapses (Fig. 4A,B). Together, these findings support the PET results and indicate that inhibitory synaptic constituents were selectively downregulated in the early stage of tau-associated pathological cascade.

\section{Tau pathology occurred exclusively in excitatory neurons of rTg4510 mice}

Selective disruption of the inhibitory synapse at 2 months of age suggests abnormalities of GABAergic interneurons in the early stage of tau pathology in rTg4510 brains. Since the CaMKII
B

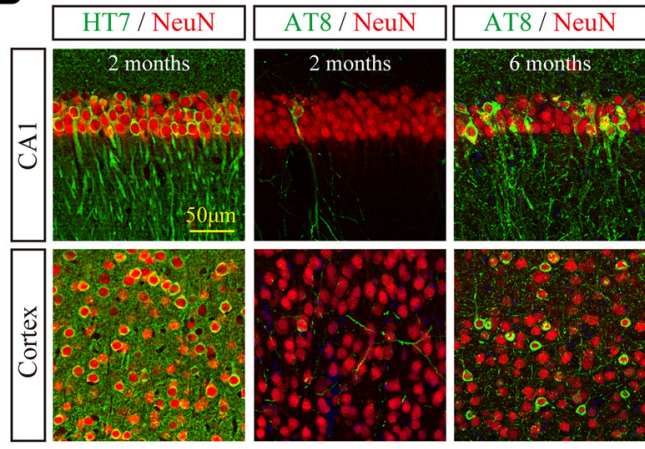

D

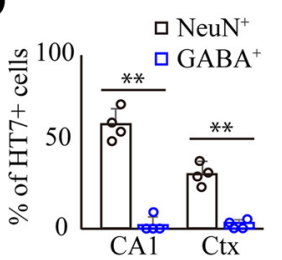

E

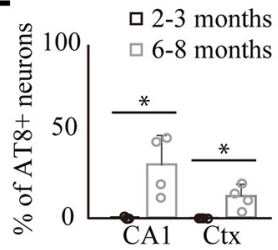

Figure 5. Excitatory neuron-specific expression and deposition of mutant tau in $\mathrm{rTg} 4510$ mouse brains. $\boldsymbol{A}$, Specific (a) (Student's brains. Data from 4 mice/genotype are demonstrated as mean \pm SD. ${ }^{*} p<0.05$ (Student's $t$ test).

promoter-mediated tet-off system drives the expression of human P301L tau in excitatory neurons of rTg4510 mouse forebrains (Mayford et al., 1996; Ramsden et al., 2005), we next decided to verify whether GABAergic interneurons demonstrate expression and accumulation of human tau in rTg4510 brains. At 2-3 months of age, histologic assessment with human tauspecific antibody HT7 revealed robust expression of human $\mathrm{P} 301 \mathrm{~L}$ mutant tau in a broad range of forebrains in $\mathrm{rTg} 4510$ mice (Fig. 5A). In hippocampus CA1 and somatosensory cortex, $>59 \%$ and $31 \%$ of $\mathrm{NeuN}^{+}$neurons demonstrated HT7 immunoreactivity, respectively (Fig. $5 B, D$ ). In good agreement with a previous study (Ramsden et al., 2005), immunoreactivity of phosphorylated tau determined by AT8 antibody was only detected in scattered neurons of the hippocampus and neocortex at an early stage, which then drastically spread through broad regions of forebrains with significant brain atrophy at 68 months of age (Fig. $5 B$ ). At this late stage, neurons harboring AT8 immunoreactivity accounted for $31 \%$ and $12 \%$ of $\mathrm{NeuN}^{+}$ neurons in CA1 and somatosensory cortex, respectively (Fig. 5E; 2-3 months vs 6-8 months, hippocampus CA1, $t_{(6)}=3.633$, $p=0.0109$; cortex, $t_{(6)}=3.526, p=0.0124$, Student's $t$ test). In contrast, $\mathrm{GABA}^{+}$neurons of CA1 and cortex did not demonstrate any expression and accumulation of tau as determined by HT7 or AT8 immunoreactivity (Fig. 5C,D; and data not shown; $\mathrm{NeuN}^{+}$vs GABA ${ }^{+}$, hippocampus CA1, $t_{(6)}=11.21, p<0.0001$; $\mathrm{NeuN}^{+}$vs $\mathrm{GABA}^{+}$, cortex, $t_{(6)}=8.943, p=0.0001$, Student's $t$ test). This result indicates that tau pathology is mainly found in excitatory neurons but not in GABAergic interneurons of rTg4510 brains. 
Synaptic, but not neuronal, loss of GABAergic interneurons at an early stage in $\mathrm{rTg} 4510$ brains

To address whether the cell density of GABAergic interneurons undergoes changes in young rTg4510 forebrains, we next examined the numbers of $\mathrm{GABA}^{+}$neurons and $\mathrm{PV}^{+}$neurons, a major subpopulation of interneurons in the forebrain, in CA1 stratum pyramidale and layer II-IV of the somatosensory cortex of 2month-old nonTg and rTg4510 brain slices. Both $\mathrm{GABA}^{+}$and $\mathrm{PV}^{+}$neurons demonstrated scattered distribution patterns across the entire forebrain (Fig. 6A), and our quantification found no difference in densities of these neurons between the two genotypes (Fig. $6 B, C$ ), suggesting that the vast majority of GABAergic interneurons, including $\mathrm{PV}^{+}$neurons, do not undergo any neuronal loss in the rTg4510 brain at this stage.

To investigate the selective degeneration of the GABAergic inhibitory synapse, we further analyzed excitatory and inhibitory synapses labeled with anti-vGluT1 and anti-VGAT antibodies, respectively, in 2-month-old nonTg and rTg4510 brains. In CA1 stratum radiatum, we identified a significant reduction in fluorescence intensity, but not in the number of $\mathrm{VGAT}^{+}$synaptic boutons in $\mathrm{rTg} 4510$ brains compared with nonTg brains (nonTg vs rTg4510, hippocampus CA1, $t_{(6)}=3.133, p=0.0203$, Student's $t$ test), while there was no difference in vGluT1 immunoreactivity between the two genotypes (Fig. $6 D-F$ ), suggesting that mature inhibitory synapses containing functional populations of $\mathrm{VGAT}^{+}$synaptic vesicles were selectively disturbed in rTg4510 brains. Although we selected the cortical layer I area to analyze the immunoreactivity of both synapses to avoid dense cell bodies, we could not detect any significant change of excitatory and inhibitory synapses in this area (Fig. 6G-I). These results indicate that some of the inhibitory synapses selectively undergo degeneration before the formation of obvious tau pathology in rTg4510 brain, while changes of these synapses in the neocortex remain uncertain.

\section{Hyperexcitability in younger $\mathrm{Tg} 4510$ brains}

Induced expression and/or nuclear accumulation of immediate early genes are well-characterized indicators for assessing neuronal network excitability. To determine excitability in the neocortical circuit of rTg4510 mice, we assessed the expression and distribution of cFos, a well-characterized immediate early gene, in hippocampal CA1 and layer II-IV of the somatosensory cortex of 2-month-old nonTg and rTg4510 brain slices. We detected increased immunoreactivity of $\mathrm{cFos}$ in the neocortical region of rTg4510 compared with age-matched nonTg mice (Fig. 7A-C nonTg vs $\mathrm{rTg} 4510$, hippocampus CA1, $t_{(14)}=2.504, p=0.0253$; nonTg vs rTg4510, cortex, $t_{(14)}=2.150, p=0.0496$, Student's $t$ test), suggesting that network excitability is enhanced at an early stage of rTg4510 brain. Importantly, we also observed that cFos expression was upregulated transiently at 2-4 months of age, followed by gradual suppression with aging (Fig. $7 D-F$; nonTg vs rTg4510, 2 months, $t_{(8)}=3.864, p=0.0048$; nonTg vs rTg4510, 4 months, $t_{(8)}=2.343, p=0.0472$; nonTg vs rTg4510, 10 months, $t_{(4)}=7.415, p=0.0018$, Student's $t$ test). No obvious alteration of $\Delta$ FosB and calbindin-D28K expression and distribution was detected in CA1 and cortex of rTg4510 brains at 2 months of age (data not shown).

\section{Discussion}

In the present study, we successfully visualized selective disruption of inhibitory, but not excitatory, synapses at an early stage of tau pathology in rTg4510 mice by PET analysis with the specific radioactive tracers $\left[{ }^{11} \mathrm{C}\right]$ flumazenil and (E) $\left[{ }^{11} \mathrm{C}\right] \mathrm{ABP} 688$. Postmortem assessment of these animal brains demonstrated that excitatory neurons exclusively express and deposit mutant tau, and these tau pathologies were followed by a degeneration of excitatory synapses and neuronal loss. Nevertheless, we clearly observed a significant decline of inhibitory synapses associated with abnormal hyperexcitability in the neocortex and hippocampus of this animal model, implicating a non-cell-autonomous mechanism of tau-induced toxicity on the GABAergic system. As epileptic seizures are frequently observed in preclinical stages of $\mathrm{AD}$ and early-onset $\mathrm{AD}$ (Vossel et al., 2017), our PET approach to the analysis of excitatory versus inhibitory synapses may offer a potential imaging-based diagnosis for hyperexcitability and excitotoxicity in the pathogenic cascade of neurodegenerative tauopathies.

Growing evidence has highlighted a significant association between tau pathology and neocortical activity (Palop and Mucke, 2016; Styr and Slutsky, 2018). In agreement with previous studies characterizing electrophysiological properties of cortical pyramidal neurons in young $\mathrm{rTg} 4510$ mice (Rocher et al., 2010; Crimins et al., 2012), our finding indicates that neocortical activity has shifted to hyperexcitable status before a noticeable formation of tau deposition. Since soluble tau oligomers accumulate even in the early phase of tau pathological stages as determined in postmortem human brains (Maeda et al., 2006; Patterson et al., 2011), the abnormal intracellular missorting of monomeric or oligomeric tau species into the somatodendritic compartment of excitatory neurons may be a sufficient trigger for the initial neuronal dysfunction, which then causes further neocortical hyperexcitability (Ittner and Ittner, 2018). Importantly, as the tau pathological stage progresses, cortical network activity gradually turns into a hypoexcitable state presumably due to a progressive loss of excitatory neurons. In this late stage, the forebrain circuit may not be able to maintain a basal level of network activity, as described in recent studies (Menkes-Caspi et al., 2015; Jackson et al., 2017; Busche et al., 2019). Therefore, we propose that neocortical excitability dynamically changes in a tau pathological stage-dependent manner. In contrast, current studies demonstrated that $\Delta \mathrm{FosB}$, a highly stable transcription factor, is upregulated in response to epileptiform activity and spontaneous seizure observed in another $\mathrm{AD}$ model mouse, which chronically suppress the gene expression of cFos and calbindin-D28K in the dentate gyrus of the hippocampus via epigenetic mechanism (Corbett et al., 2017; You et al., 2017). Our preliminary analysis revealed no obvious alteration of $\Delta \mathrm{FosB}$ and calbindin-D28K in rTg4510 brains; and hence, the animal model appears to have hyperexcitability but not spontaneous seizures. This may be due to different pathological conditions between the two independent mouse models, as their transgenic mice develop progressive $\mathrm{A} \beta$ pathology without any tau accumulation (Palop et al., 2007).

Notwithstanding our hypothesis regarding the disruption of inhibitory synapses, several groups have claimed a selective vulnerability of excitatory neurons to tau pathology (Roselli and Caroni, 2015; Fu et al., 2018). Notably, Fu et al. (2019) recently demonstrated a specific tau homeostasis signature in excitatory neurons by single-nucleus RNA-sequencing analysis of human brains, identifying that the expression level of BAG3, a facilitator of autophagy, in excitatory neurons is much lower than that in inhibitory neurons or glial cells, thereby indicating that excitatory neurons have specific intracellular environment that is more vulnerable to tau accumulation and ultimate neuronal loss. In terms of autonomous cell death associated with tau depositions, 
we still suppose that excitatory neurons are primarily vulnerable to pathological tau toxicity and progressive neuronal loss as observed in rTg4510 brains, as little tau expression and deposition in soma of $\mathrm{GABA}^{+}$interneurons were observed until 8 months of age (Fig. 5). Nonetheless, as the determination of precise cell viability and composition in postmortem brain tissues with severe atrophy and pathologies are difficult, PET assessment of excitatory versus inhibitory neuronal composition may provide more definitive information concerning this crucial issue.

The selective impairment of inhibitory synapses in the early stage of tau pathology should be considered separately from the aspect of neuronal loss. We should consider three possibilities: First, low order species of tau aggregates may spread from excitatory neurons to surrounding inhibitory synaptic termini via synaptic connection as proposed in a recent tau propagation hypothesis (Goedert et al., 2017). In this case, such tau species can be released and selectively damage the receptor and adhesion molecules in the inhibitory synapse cleft, or they can further experience uptake by GABAergic interneurons and disrupt inhibitory synapses from inside the cells. Second, tau accumulation in excitatory neurons may disrupt intracellular trafficking and/or secretion of trans-synaptic signaling molecules essential for the maintenance of inhibitory synapses (Regehr et al., 2009). This possibility is supported by studies describing that tau overexpression and aggregates disturb microtubule-dependent trafficking of cargo molecules and kinase activity (Stamer et al., 2002; Morris et al., 2011). Third, astrocytes and microglia may be involved in this process. We previously found that inflammatory activation of both cells occurs before pathological tau accumulation in several tau transgenic mice (Yoshiyama et al., 2007; Ishikawa et al., 2018), and a recent study also reported that activated microglia can externalize tau aggregates and enhance tau propagation (Luo et al., 2015). Thus, activated microglia induced by an early stage of tau pathology may facilitate selective elimination of inhibitory synapses, as is currently being debated (Um, 2017). In either case, the molecular events associated with the selective impairment of inhibitory synapses could be an essential target for early diagnosis and pharmacological treatment, and additional efforts will be necessary to dissect the details.

Leuzy et al. (2016) recently reported reduced availability of $\left[{ }^{11} \mathrm{C}\right] \mathrm{ABP} 688$ and hypometabolism associated with gray matter
A

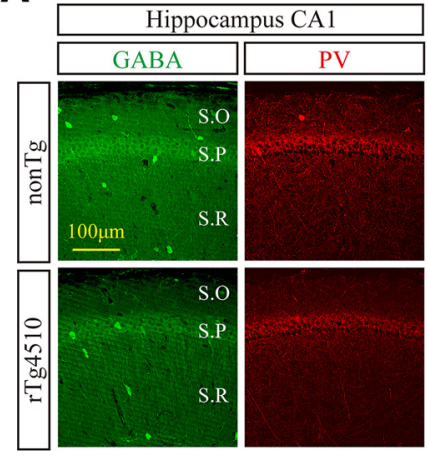

D

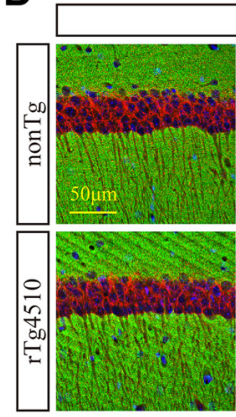

G

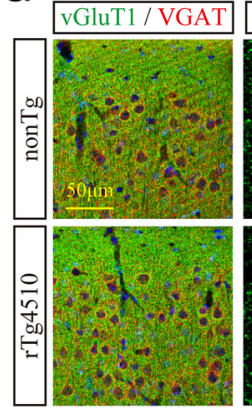

vGluT1 / VGAT
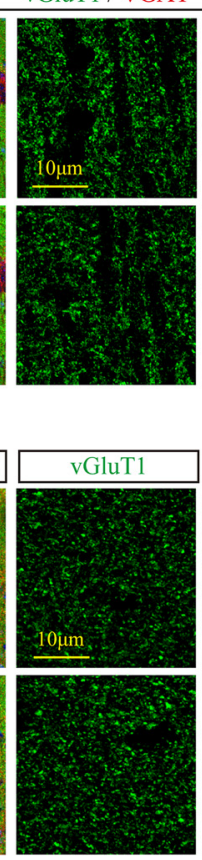
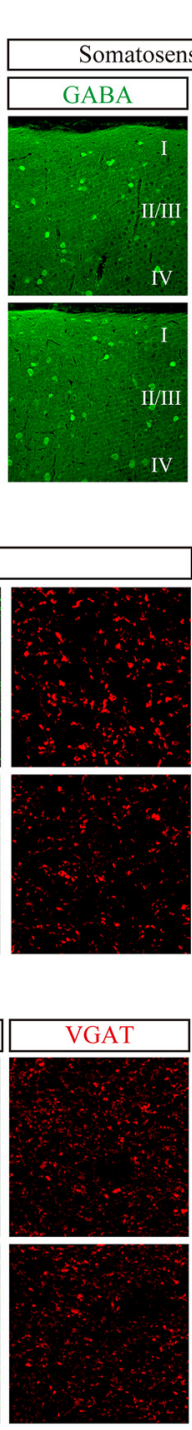

B

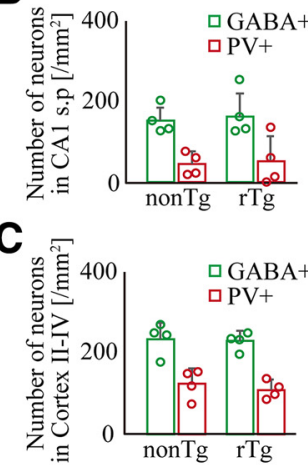

E

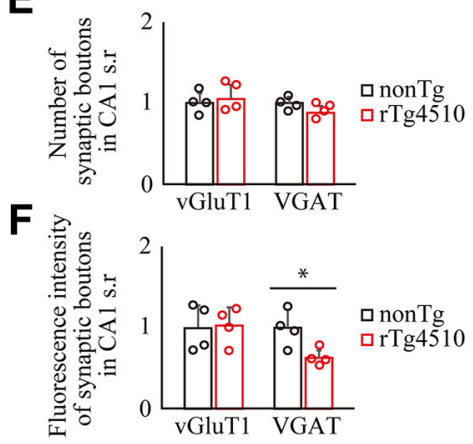

$\mathrm{H}$

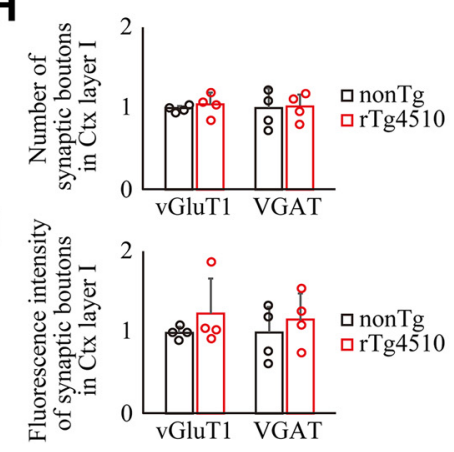

Figure 6. Synaptic loss, but not neuronal loss, of GABAergic interneurons precedes tau-associated pathology in young rTg4510 brains. A-C, Distribution of GABAergic interneurons in 2- to 3-month-old nonTg (top panels) and rTg4510 (bottom panels) forebrain was immunohistochemically examined by anti-GABA and anti-PV antibodies. $\boldsymbol{A}$, Representative slice images immunolabeled with antibodies to GABA (green) and PV (red) in hippocampus CA1 (left panels) and somatosensory cortex (right panels). S.0, Stratum oriens; S.P, stratum pyramidale; S.R, stratum radiatum. B, C, Cell densities of GABA ${ }^{+}$and PV ${ }^{+}$neurons in hippocampus $(A 1$ stratum pyramidale $(\boldsymbol{B})$ and somatosensory cortex $(\boldsymbol{C})$ of nonTg and $\mathrm{rTg} 4510$. Data from 4 mice/genotype are demonstrated as mean \pm SD. $\boldsymbol{D}-\boldsymbol{F}$, Distribution of excitatory and inhibitory synapses in hippocampus CA1 of nonTg (top panels) and rTg4510 (bottom panels) was assessed by coimmunostaining with antibodies to vGluT1 (green) and VGAT (red), respectively. $\boldsymbol{D}$, Representative low- (left) and high-magnification images (middle and right). $\boldsymbol{E}, \boldsymbol{F}$, Number $(\boldsymbol{E})$ and total immunoreactivity $(\boldsymbol{F})$ of $\mathrm{vGluT1}^{+}$and $\mathrm{VGAT}^{+}$synaptic boutons in hippocampus CA1 stratum radiatum of nonTg and $\mathrm{rTg} 4510$ mice. Data from 4 mice/genotype are demonstrated as mean \pm SD. Mean value of nonTg mice was set as $1 .{ }^{*} p<0.05$ (Student's $t$ test). G-I, Distribution of excitatory and inhibitory synapses in somatosensory cortex of nonTg (top panels) and rTg4510 (bottom panels) was assessed by coimmunostaining with antibodies to vGluT1 (green) and VGAT (red), respectively. $\mathbf{G}$, Representative low- (left) and high-magnification images (middle and right). $\boldsymbol{H}, \boldsymbol{I}$, Number $(\boldsymbol{H})$ and total immunoreactivity $(\boldsymbol{I})$ of vGluT1 ${ }^{+}$and $\mathrm{VGAT}^{+}$synaptic boutons in cortical layer I of nonTg and $\mathrm{rTg} 4510$ mice. Data from 4 mice/genotype are demonstrated as mean \pm SD. Mean value of nonTg mice was set as 1 .

atrophy in the brains of behavioral variant frontotemporal dementia. In line with their result, we also found reduced $\mathrm{BP}_{\mathrm{ND}}$ of (E)- $\left[{ }^{11} \mathrm{C}\right] \mathrm{ABP} 688$ in parallel with brain atrophy at $>5-6$ months of age, indicating that this PET tracer can suitably capture abnormalities of excitatory neurons and synapses in the tau-associated disease progress. Interestingly, biochemical protein levels of mGluR5 in postmortem brain tissues were relatively constant between age 2 and 8 months, suggesting that our PET imaging 
A

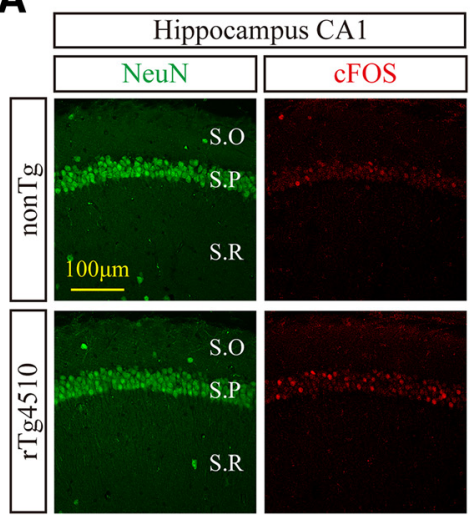

D

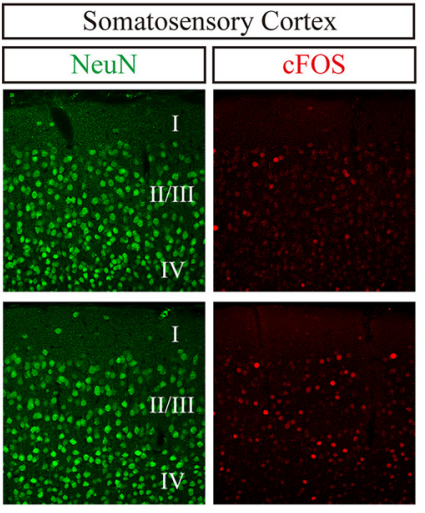

$\mathbf{E}$

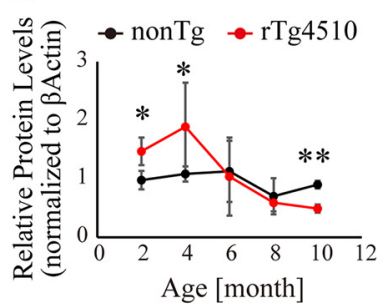

B
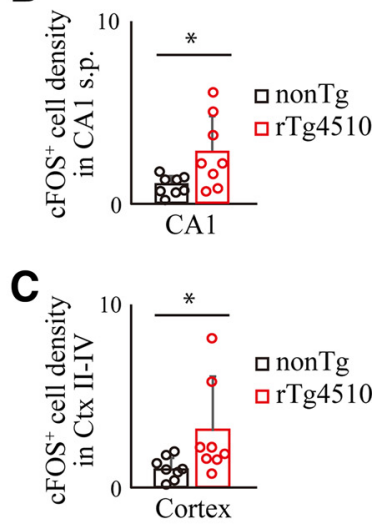

$\mathbf{F}$

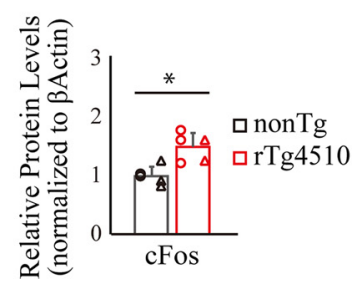

Figure 7. Enhanced cFos level in young rTg4510 brains. A, Representative slice images immunolabeled with anti-NeuN and anti-cFos antibodies in hippocampus CA1 (left panels) and somatosensory cortex (right panels). S.0, Stratum oriens; S.P, stratum pyramidale; S.R, stratum radiatum. $\boldsymbol{B}, \boldsymbol{C}$, Densities of cFos ${ }^{+}$neurons in hippocampus CA1 stratum pyramidale (B) or somatosensory cortex (C). Data from 8 mice/genotype are demonstrated as mean \pm SD. Mean value of nonTg mice was set as $1 .{ }^{*} p<0.05$ (Student's $t$ test). D, Representative immunoblot demonstrating enhanced levels of cFos protein in young rTg4510 brains. $\boldsymbol{E}$, Age-dependent alteration of cFos levels was quantified and normalized by the level of $\beta$-actin. Data from 3-5 independent mouse brains are plotted as mean \pm SD. ${ }^{*} p<0.05 ;{ }^{* *} p<0.01$; Student's $t$ test. $\boldsymbol{F}$, Enhanced levels of cFos protein in forebrain homogenate from 2-month-old rTg4510 brains. Each circle represents an individual male mouse. Each triangle represents an individual female mouse. Mean value of nonTg mice was set as $1 .{ }^{*} p<0.05$ (Student's $t$ test).

A

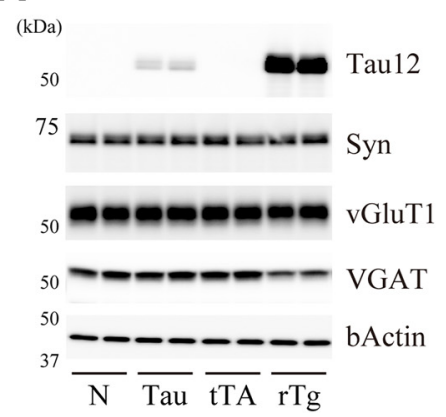

B

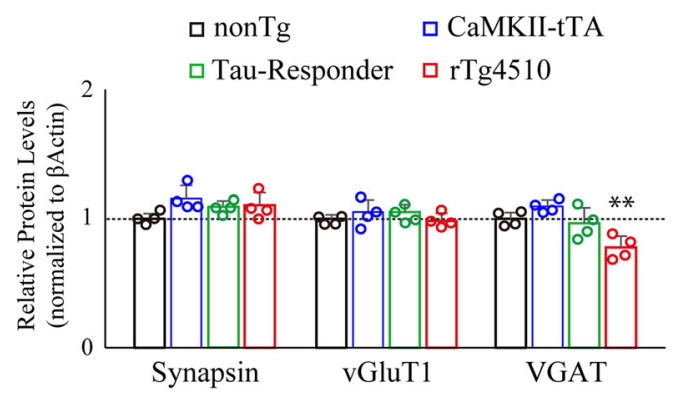

Figure 8. Selective disruption of inhibitory synapses was not observed in CaMKIl-tTA and Tau-Responder lines. $\boldsymbol{A}$, Forebrain homogenates from all genotypes obtained by cross-breeding of Tau-Responder (tet0-MAPT*P301L) and (aMKII-tTA (Camk2a-tTA) lines were analyzed by immunoblotting at 2 months of age. Representative gel images demonstrate that VGAT protein level was specifically reduced in rTg4510 mice but not in CaMKII-tTA mice or Tau-Responder mice compared with nonTg. $\boldsymbol{B}$, Data from nonTg $(n=4)$, CKII-tTA $(n=4)$, Tau-Responder $(n=4)$, and $\mathrm{rTg} 4510(n=4)$ mouse brains are demonstrated as mean \pm SD. Mean value of nonTg mice was set as $1 .{ }^{* *} p<0.01$ (nonTg vs rTg4510, VGAT, $F_{(3,10)}=10.66$, $p=0.0062$, one-way ANOVA post hoc Dunnett test).

may capture a more dynamic status of mGluR5 receptor in living animal brains. As $(\mathrm{E})-\left[{ }^{11} \mathrm{C}\right] \mathrm{ABP} 688$ interacts with an allosteric site that is segregated from glutamate binding site of mGluR5, we expect that the changes of $(\mathrm{E})-\left[{ }^{11} \mathrm{C}\right] \mathrm{ABP} 688 \mathrm{BP} \mathrm{ND}$ may reflect either conformation change or subcellular redistribution of mGluR5 associated with intracellular tau accumulation (Hoover et al., 2010; Ittner et al., 2010). Similar to these findings, functional loss of $\mathrm{GABA}_{\mathrm{A}}$ receptor accompanied by selective downregulation of its subunits was also identified in tissue membrane from postmortem AD brain (Limon et al., 2012), indicating that tau-associated pathophysiology may contribute proper subunit assembly of this high molecular receptor complex with alteration of $\left[{ }^{11} \mathrm{C}\right]$ flumazenil binding capability. Since a recent study reevaluated the beneficial utility of $\left[{ }^{11} \mathrm{C}\right]$ flumazenil for the early detection of $\mathrm{AD}$ (Pascual et al., 2012), PET assessment of these receptor dynamics may offer a more advanced applicability of PET for the visualization of complicated brain functions and dysfunctions in both animal models and humans.

A recent study demonstrated that a large genomic fragment of $f g f 14$ on chromosome 14 was replaced by tau transgenicinsertion/deletion (INDEL) mutation in rTg4510 mice, which consequently dysregulates the expression pattern of FGF14 splice variants and impacts the progress of neuronal loss and behavioral abnormalities observed in this tauopathy model $\backslash$ (Gamache et al., 2019). In addition, they also pointed out disruptions of five annotated genes on chromosome 12 in tTA transgenic-INDEL that may potentially affect a part of abnormalities unrelated to tau pathology in the $\mathrm{rTg} 4510$ model, implying that these kinds of mutagenesis are needed for directing careful attention to control strategies. To avoid any misinterpretation of our findings, we performed biochemical assessment of brain samples from all genotypes obtained by cross-breeding of tetO-MAPT ${ }^{\star}$ P301L and Camk2a-tTA lines, and found significant reduction of VGAT in $\mathrm{rTg} 4510$ (tetO-MAPT ${ }^{\star} \mathrm{P} 301 \mathrm{~L}^{+} / \mathrm{Camk} 2 \mathrm{a}-$ $\mathrm{tTA}^{+}$) mice, but not in tau responder (tetO-MAPT ${ }^{\star} \mathrm{P}^{2} 31 \mathrm{~L}^{+} /$ 
Camk2a-tTA ${ }^{-}$) or CaMKII-tTA (tetO-MAPT ${ }^{*}$ P301L $^{-} /$Camk2a$\mathrm{tTA}^{+}$) mice, compared with nonTg (tetO-MAPT*P301L/Camk2atTA $^{-}$) mice (Fig. 8), supporting the idea that selective disruption of the GABAergic system is tau pathology-dependent. Nonetheless, for coordinating high reliability in the assessment of disease mechanisms using genetically engineered models, strategy to overexpress mutant tau from a targeted locus would provide fundamental insight into the next stage of animal modeling research.

In conclusion, we identified and visualized selective synaptic dysfunction of GABAergic interneurons in the early stage of tauassociated abnormalities. This pathway can be involved in the process of pathological tau spreading and neuronal loss, and our findings provide fundamental insight into the molecular target of disease-modifying therapy. Growing evidence indicates that disrupted exhibitory/inhibitory balance of neocortical circuits is also involved in neurodevelopmental and psychiatric disorders, and a noninvasive PET assessment of inhibitory versus excitatory synapses may be beneficial for the imaging-based diagnosis of a broader range of neurologic disorders in the future.

\section{References}

Arriagada PV, Growdon JH, Hedley-Whyte ET, Hyman BT (1992) Neurofibrillary tangles but not senile plaques parallel duration and severity of Alzheimer's disease. Neurology 42:631-639.

Braak H, Braak E (1991) Neuropathological stageing of Alzheimer-related changes. Acta Neuropathol 82:239-259.

Busche MA, Wegmann S, Dujardin S, Commins C, Schiantarelli J, Klickstein N, Kamath TV, Carlson GA, Nelken I, Hyman BT (2019) Tau impairs neural circuits, dominating amyloid-beta effects, in Alzheimer models in vivo. Nat Neurosci 22:57-64.

Corbett BF, You JC, Zhang X, Pyfer MS, Tosi U, Iascone DM, Petrof I, Hazra A, Fu CH, Stephens GS, Ashok AA, Aschmies S, Zhao L, Nestler EJ, Chin J (2017) DeltaFosB regulates gene expression and cognitive dysfunction in a mouse model of Alzheimer's disease. Cell Rep 20:344-355.

Crimins JL, Rocher AB, Luebke JI (2012) Electrophysiological changes precede morphological changes to frontal cortical pyramidal neurons in the rTg4510 mouse model of progressive tauopathy. Acta Neuropathol 124:777-795.

Fu H, Hardy J, Duff KE (2018) Selective vulnerability in neurodegenerative diseases. Nat Neurosci 21:1350-1358.

Fu H, Possenti A, Freer R, Nakano Y, Hernandez Villegas NC, Tang M, Cauhy PV, Lassus BA, Chen S, Fowler SL, Figueroa HY, Huey ED, Johnson GV, Vendruscolo M, Duff KE (2019) A tau homeostasis signature is linked with the cellular and regional vulnerability of excitatory neurons to tau pathology. Nat Neurosci 22:47-56.

Gamache J, Benzow K, Forster C, Kemper L, Hlynialuk C, Furrow E, Ashe KH, Koob MD (2019) Factors other than hTau overexpression that contribute to tauopathy-like phenotype in rTg4510 mice. Nat Commun 10:2479.

García-Cabrero AM, Guerrero-López R, Giráldez BG, Llorens-Martín M, Avila J, Serratosa JM, Sánchez MP (2013) Hyperexcitability and epileptic seizures in a model of frontotemporal dementia. Neurobiol Dis 58:200208.

Giannakopoulos P, Herrmann FR, Bussiere T, Bouras C, Kovari E, Perl DP, Morrison JH, Gold G, Hof PR (2003) Tangle and neuron numbers, but not amyloid load, predict cognitive status in Alzheimer's disease. Neurology 60:1495-1500.

Goedert M, Masuda-Suzukake M, Falcon B (2017) Like prions: the propagation of aggregated tau and alpha-synuclein in neurodegeneration. Brain 140:266-278.

Hoover BR, Reed MN, Su J, Penrod RD, Kotilinek LA, Grant MK, Pitstick R, Carlson GA, Lanier LM, Yuan LL, Ashe KH, Liao D (2010) Tau mislocalization to dendritic spines mediates synaptic dysfunction independently of neurodegeneration. Neuron 68:1067-1081.

Iqbal K, Liu F, Gong CX (2016) Tau and neurodegenerative disease: the story so far. Nat Rev Neurol 12:15-27.

Ishikawa A, Tokunaga M, Maeda J, Minamihisamatsu T, Shimojo M, Takuwa H, Ono M, Ni R, Hirano S, Kuwabara S, Ji B, Zhang MR, Aoki I, Suhara T, Higuchi M, Sahara N (2018) In vivo visualization of tau accumulation, microglial activation, and brain atrophy in a mouse model of tauopathy rTg4510. J Alzheimers Dis 61:1037-1052.

Ittner A, Ittner LM (2018) Dendritic tau in Alzheimer's disease. Neuron 99:13-27.

Ittner LM, Ke YD, Delerue F, Bi M, Gladbach A, van Eersel J, Wölfing H, Chieng BC, Christie MJ, Napier IA, Eckert A, Staufenbiel M, Hardeman E, Götz J (2010) Dendritic function of tau mediates amyloid-beta toxicity in Alzheimer's disease mouse models. Cell 142:387-397.

Jackson JS, Witton J, Johnson JD, Ahmed Z, Ward M, Randall AD, Hutton ML, Isaac JT, O'Neill MJ, Ashby MC (2017) Altered synapse stability in the early stages of tauopathy. Cell Rep 18:3063-3068.

Jankowsky JL, Zheng H (2017) Practical considerations for choosing a mouse model of Alzheimer's disease. Mol Neurodegener 12:89.

Kawamura K, Yamasaki T, Kumata K, Furutsuka K, Takei M, Wakizaka H, Fujinaga M, Kariya K, Yui J, Hatori A, Xie L, Shimoda Y, Hashimoto H, Hayashi K, Zhang MR (2014) Binding potential of (E)-[(1)(1)C]ABP688 to metabotropic glutamate receptor subtype 5 is decreased by the inclusion of its (1)(1)C-labelled Z-isomer. Nucl Med Biol 41:17-23.

Kimura T, Whitcomb DJ, Jo J, Regan P, Piers T, Heo S, Brown C, Hashikawa T, Murayama M, Seok H, Sotiropoulos I, Kim E, Collingridge GL, Takashima A, Cho K (2014) Microtubule-associated protein tau is essential for long-term depression in the hippocampus. Philos Trans R Soc Lond B Biol Sci 369:20130144.

Kopeikina KJ, Wegmann S, Pitstick R, Carlson GA, Bacskai BJ, Betensky RA, Hyman BT, Spires-Jones TL (2013) Tau causes synapse loss without disrupting calcium homeostasis in the rTg4510 model of tauopathy. PLoS One 8:e80834.

Leuzy A, Zimmer ER, Dubois J, Pruessner J, Cooperman C, Soucy JP, Kostikov A, Schirmaccher E, Desautels R, Gauthier S, Rosa-Neto P (2016) In vivo characterization of metabotropic glutamate receptor type 5 abnormalities in behavioral variant FTD. Brain Struct Funct 221:13871402.

Limon A, Reyes-Ruiz JM, Miledi R (2012) Loss of functional GABA(A) receptors in the Alzheimer diseased brain. Proc Natl Acad Sci USA 109:10071-10076.

Liu S, Shen Y, Shultz SR, Nguyen A, Hovens C, Adlard PA, Bush AI, Chan J, Kwan P, O'Brien TJ, Jones NC (2017) Accelerated kindling epileptogenesis in Tg4510 tau transgenic mice, but not in tau knockout mice. Epilepsia 58:e136-e141.

Luo W, Liu W, Hu X, Hanna M, Caravaca A, Paul SM (2015) Microglial internalization and degradation of pathological tau is enhanced by an anti-tau monoclonal antibody. Sci Rep 5:11161.

Maeda S, Sahara N, Saito Y, Murayama S, Ikai A, Takashima A (2006) Increased levels of granular tau oligomers: an early sign of brain aging and Alzheimer's disease. Neurosci Res 54:197-201.

Maeda S, Djukic B, Taneja P, Yu GQ, Lo I, Davis A, Craft R, Guo W, Wang X, Kim D, Ponnusamy R, Gill TM, Masliah E, Mucke L (2016) Expression of A152T human tau causes age-dependent neuronal dysfunction and loss in transgenic mice. EMBO Rep 17:530-551.

Maruyama M, Shimada H, Suhara T, Shinotoh H, Ji B, Maeda J, Zhang MR, Trojanowski JQ, Lee VM, Ono M, Masamoto K, Takano H, Sahara N, Iwata N, Okamura N, Furumoto S, Kudo Y, Chang Q, Saido TC, Takashima A, et al. (2013) Imaging of tau pathology in a tauopathy mouse model and in Alzheimer patients compared to normal controls. Neuron 79:1094-1108.

Mayford M, Bach ME, Huang YY, Wang L, Hawkins RD, Kandel ER (1996) Control of memory formation through regulated expression of a CaMKII transgene. Science 274:1678-1683.

Menkes-Caspi N, Yamin HG, Kellner V, Spires-Jones TL, Cohen D, Stern EA (2015) Pathological tau disrupts ongoing network activity. Neuron 85:959-966.

Morris M, Maeda S, Vossel K, Mucke L (2011) The many faces of tau. Neuron 70:410-426.

Müller Herde A, Benke D, Ralvenius WT, Mu L, Schibli R, Zeilhofer HU, Krämer SD (2017) GABAA receptor subtypes in the mouse brain: regional mapping and diazepam receptor occupancy by in vivo [(18)F]flumazenil PET. Neuroimage 150:279-291.

Nishino A, Tajima Y, Takuwa H, Masamoto K, Taniguchi J, Wakizaka H, Kokuryo D, Urushihata T, Aoki I, Kanno I, Tomita Y, Suzuki N, Ikoma $\mathrm{Y}$, Ito H (2016) Long-term effects of cerebral hypoperfusion on neural density and function using misery perfusion animal model. Sci Rep 6:25072. 
Palop JJ, Mucke L (2016) Network abnormalities and interneuron dysfunction in Alzheimer disease. Nat Rev Neurosci 17:777-792.

Palop JJ, Chin J, Roberson ED, Wang J, Thwin MT, Bien-Ly N, Yoo J, Ho KO, Yu GQ, Kreitzer A, Finkbeiner S, Noebels JL, Mucke L (2007) Aberrant excitatory neuronal activity and compensatory remodeling of inhibitory hippocampal circuits in mouse models of Alzheimer's disease. Neuron 55:697-711.

Pascual B, Prieto E, Arbizu J, Marti-Climent JM, Peñuelas I, Quincoces G, Zarauza R, Pappatà S, Masdeu JC (2012) Decreased carbon-11-flumazenil binding in early Alzheimer's disease. Brain 135:2817-2825.

Patterson KR, Remmers C, Fu Y, Brooker S, Kanaan NM, Vana L, Ward S, Reyes JF, Philibert K, Glucksman MJ, Binder LI (2011) Characterization of prefibrillar Tau oligomers in vitro and in Alzheimer disease. J Biol Chem 286:23063-23076.

Ramsden M, Kotilinek L, Forster C, Paulson J, McGowan E, SantaCruz K, Guimaraes A, Yue M, Lewis J, Carlson G, Hutton M, Ashe KH (2005) Age-dependent neurofibrillary tangle formation, neuron loss, and memory impairment in a mouse model of human tauopathy (P301L). J Neurosci 25:10637-10647.

Regehr WG, Carey MR, Best AR (2009) Activity-dependent regulation of synapses by retrograde messengers. Neuron 63:154-170.

Roberson ED, Scearce-Levie K, Palop JJ, Yan F, Cheng IH, Wu T, Gerstein H, Yu GQ, Mucke L (2007) Reducing endogenous tau ameliorates amyloid beta-induced deficits in an Alzheimer's disease mouse model. Science 316:750-754.

Rocher AB, Crimins JL, Amatrudo JM, Kinson MS, Todd-Brown MA, Lewis J, Luebke JI (2010) Structural and functional changes in tau mutant mice neurons are not linked to the presence of NFTs. Exp Neurol 223:385393.

Roselli F, Caroni P (2015) From intrinsic firing properties to selective neuronal vulnerability in neurodegenerative diseases. Neuron 85:901-910.

Santacruz K, Lewis J, Spires T, Paulson J, Kotilinek L, Ingelsson M, Guimaraes A, DeTure M, Ramsden M, McGowan E, Forster C, Yue M, Orne J, Janus C, Mariash A, Kuskowski M, Hyman B, Hutton M, Ashe $\mathrm{KH}$ (2005) Tau suppression in a neurodegenerative mouse model improves memory function. Science 309:476-481.

Shimojo M, Madara J, Pankow S, Liu X, Yates J, Südhof TC, Maximov A (2019) Synaptotagmin-11 mediates a vesicle trafficking pathway that is essential for development and synaptic plasticity. Genes Dev 33:365-376.
Spires-Jones TL, Hyman BT (2014) The intersection of amyloid beta and tau at synapses in Alzheimer's disease. Neuron 82:756-771.

Stamer K, Vogel R, Thies E, Mandelkow E, Mandelkow EM (2002) Tau blocks traffic of organelles, neurofilaments, and APP vesicles in neurons and enhances oxidative stress. J Cell Biol 156:1051-1063.

Styr B, Slutsky I (2018) Imbalance between firing homeostasis and synaptic plasticity drives early-phase Alzheimer's disease. Nat Neurosci 21:463473.

Tatsumi T, Takayama K, Ishii S, Yamamoto A, Hara T, Minami N, Miyasaka N, Kubota T, Matsuura A, Itakura E, Tsukamoto S (2018) Forced lipophagy reveals that lipid droplets are required for early embryonic development in mouse. Development 145:dev161893.

Tokunaga M, Seneca N, Shin RM, Maeda J, Obayashi S, Okauchi T, Nagai Y, Zhang MR, Nakao R, Ito H, Innis RB, Halldin C, Suzuki K, Higuchi M, Suhara T (2009) Neuroimaging and physiological evidence for involvement of glutamatergic transmission in regulation of the striatal dopaminergic system. J Neurosci 29:1887-1896.

Um JW (2017) Roles of glial cells in sculpting inhibitory synapses and neural circuits. Front Mol Neurosci 10:381.

Vossel KA, Tartaglia MC, Nygaard HB, Zeman AZ, Miller BL (2017) Epileptic activity in Alzheimer's disease: causes and clinical relevance. Lancet Neurol 16:311-322.

Yamasaki T, Fujinaga M, Kawamura K, Furutsuka K, Nengaki N, Shimoda Y, Shiomi S, Takei M, Hashimoto H, Yui J, Wakizaka H, Hatori A, Xie L, Kumata K, Zhang MR (2016) Dynamic changes in striatal mGluR1 but not mGluR5 during pathological progression of Parkinson's disease in human alpha-synuclein A53T transgenic rats: a multi-PET imaging study. J Neurosci 36:375-384.

Yoshiyama Y, Higuchi M, Zhang B, Huang SM, Iwata N, Saido TC, Maeda J, Suhara T, Trojanowski JQ, Lee VM (2007) Synapse loss and microglial activation precede tangles in a P301S tauopathy mouse model. Neuron 53:337-351.

You JC, Muralidharan K, Park JW, Petrof I, Pyfer MS, Corbett BF, LaFrancois JJ, Zheng Y, Zhang X, Mohila CA, Yoshor D, Rissman RA, Nestler EJ, Scharfman HE, Chin J (2017) Epigenetic suppression of hippocampal calbindin-D28k by DeltaFosB drives seizure-related cognitive deficits. Nat Med 23:1377-1383.

Zhao X, Kotilinek LA, Smith B, Hlynialuk C, Zahs K, Ramsden M, Cleary J, Ashe KH (2016) Caspase-2 cleavage of tau reversibly impairs memory. Nat Med 22:1268-1276. 